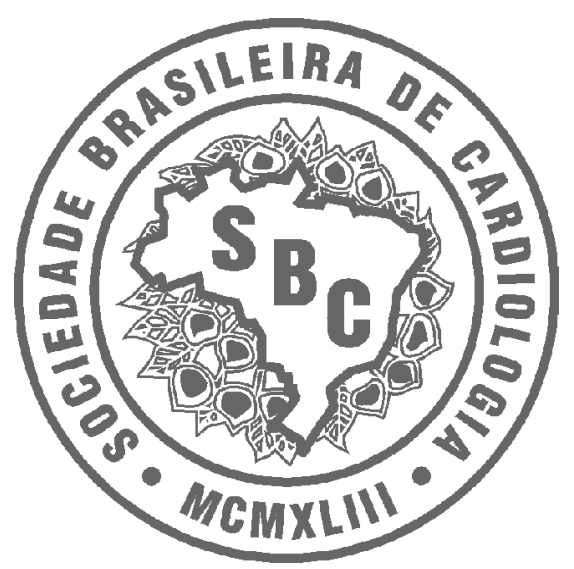

\title{
Normatização dos Equipamentos e das Técnicas para a Realização de Exames de Ultra-Sonografia Vascular
}

\author{
Editor \\ Luciano Herman Juaçaba Belem \\ Membros \\ Antonio Carlos Santos Nogueira \\ Claudio Domenico Schettino \\ Marcio Vinicius Lins Barros \\ Monica Luiza de Alcantara \\ Paulo Cesar de Carvalho Studart \\ Paula Pimentel de Araújo \\ Salomon Israel do Amaral \\ Simone Barretto
}

Coordenador

Jorge Ilha Guimarães 


\section{1 - Introdução}

Esta normatização foi elaborada por membros do Departamento de Ecocardiografia da Sociedade Brasileira de Cardiologia, com o objetivo de propor padrões mínimos quanto à utilização de equipamentos de ecocardiografia em exames vasculares, assim como estabelecer conceitos e protocolos, cientificamente, aceitos e recomendados na literatura médica. Foge ao seu escopo a abordagem de todos os temas atualmente estudados pela ultra-sonografia vascular, tendo sido escolhidos aqueles mais diretamente relacionados ao cardiologista.

Ressalte-se que esse tipo de exame pode ser feito por profissionais oriundos das mais diversas áreas, como radiologia, angiologia e cirurgia vascular, além daqueles com formação cardiológica. Em vários países, têm sido realizados acordos entre as socieda. des das diversas especialidades envolvidas, objetivando normatizar e certificar os profissionais aptos para a realização deste exame.

Na presente normatização, serão utilizados os seguintes Graus de Recomendação: I - quando existe efetividade comprovada e indicação unânime; Ila - quando a maioria aprova a indicação, embora não haja unanimidade; Ilb -quando a indicação é razoável, embora exista divisão de opiniões; III - quando a maioria não aprova a indicação.

Os temas escolhidos e respectivos editores associados foram:

1) Introdução e Equipamentos - Luciano Belem, Simone Barretto

2) Carótidas e Vertebrais - Paula Pimentel, Claudio Domenico Sahione Schettino, Luciano Belem

3) Aorta e Artérias Renais - Antonio Carlos Santos Nogueira

4) Artérias dos Membros Inferiores - Marcio Vinicius Lins Barros

5) Trombose Venosa Profunda - Salomon Israel do Amaral

6) Uso de Contraste - Monica Luiza de Alcantara.

Encarregado da revisão, Paulo Cesar de Carvalho Studart.

Diversas denominações têm sido aplicadas aos exames vasculares que utilizam a ultra-sonografia, combinando a imagem com a obtenção de fluxos pelo método Doppler. Considerou-se que, independentemente da nomenclatura, todos os exames devem ser feitos com o emprego do mapeamento de fluxos a cores.

Os termos comumente empregados para tal tipo de exame são: eco Doppler colorido, eco Doppler com mapeamento de fluxo a cores, ultra-sonografia com mapeamento de fluxo a cores, dúplex scan, dúplex scan colorido seguido do segmento vascular a ser examinado. Para fins de simplificação, adotaremos dúplex scan colorido como o exame completo, englobando imagem bidimensional, Doppler espectral pulsado e mapeamento de fluxo a cores.

\section{2 - Equipamento}

Num país com dimensões continentais como o Brasil e com diversas realidades econômicas, torna-se difícil estabelecer o que seja um equipamento ideal. Não seria justo exigir que um pequeno laboratório no interior do país tenha o mesmo equipamento que um laboratório com grande número de exames, num grande centro. Alguns tipos de exames, mesmo com equipamentos não ideais, podem fornecer informações importantes, conforme as usadas nos grandes centros na década de 80. Esta normativa pretende apenas sugerir o que é um equipamento com os recursos mínimos adequados e o que é o ideal para realizar, com seguran- ça e acurácia, os exames cujos protocolos serão expostos a seguir, sempre lembrando que esta área está em constante evolução.

\section{1 - Console}

Deve ser capaz de realizar os seguintes tipos de imagem e Doppler: a) imagem bidimensional; b) mapeamento de fluxo a cores; c) Doppler espectral pulsátil; d) Doppler espectral contínuo (para alguns tipos de transdutores, não sendo fundamental para exames vasculares); e) power Doppler também conhecido como power angio, Doppler energia, forma de mapeamento de fluxos sem indicar a direção, baseado na amplitude do sinal (recurso ideal, mas não fundamental para o exame)

\section{2 - Aplicativos (softwares)}

O equipamento deverá ter, entre as suas opções de aplicativos, configurações (presets) pré-estabelecidas, específicas para cada tipo de estudo, agilizando e facilitando a tarefa do examinador: a) carótidas (com ou sem a correção automática do ângulo a 60 graus); b) aorta abdominal e artérias renais; c) arterial periférico; d) venoso.

\section{3 - Transdutores multifreqüenciais ou de banda larga}

a) linear: freqüência ideal entre 5 e $10 \mathrm{Mhz}$ (em algumas circunstâncias, freqüências de 4 ou 12 Mhz podem úteis); b) convexo - freqüência ideal entre 2 e $5 \mathrm{Mhz}$, podendo ser substituído com pouca perda de qualidade no exame por transdutor setorial (ou microconvexo com freqüência similar, usado em ecocardiografia); c) setorial de baixa freqüência: 2 a 4 Mhz (útil quando há necessidade de Doppler contínuo em estudos arteriais abdominais - não é fundamental); d) setorial de alta freqüência: 4 a 10 Mhz (útil em lesões proximais de artérias na base do pescoço e lesões distais de ramo interno de carótidas - transdutor ideal, mas não fundamental)

\section{4 - Cálculos}

Os equipamentos devem possuir aplicativos para realizar, pelo menos, algumas medidas básicas: a) controle para correção do ângulo, fundamental para a medida correta da velocidade do fluxo; b) escala de velocidade ao lado do traçado do Doppler espectral (escalas exclusivamente em Khz não devem mais ser aceitas); c) medidas de velocidades máximas e médias; d) medidas de distância no eco bidimensional e Doppler a cores; e) medidas de áreas no eco bidimensional e Doppler a cores; f) cálculo dos índices de resistência e pulsatilidade (ideal, mas não fundamental); g) percentual de estenose pela distância e pela área (ideal, mas não fundamental).

\section{5 - Orientação da imagem}

Preferencialmente, a orientação das imagens na tela e nos registros deverá obedecer à padronização utilizada nos exames radiológicos, ou seja, no eixo longitudinal, as estruturas com direção cefálica ou cranial estarão à esquerda da tela e, no eixo transversal, as estruturas esquerdas estarão à direita da tela.

A orientação utilizada nos exames cardiológicos (ecocardiografia), em que, no eixo longitudinal, as estruturas com direção cefálica ou cranial estarão à direita da tela, poderá ser utilizada, desde que este tipo de orientação (menos usado) fique claro nos registros. 


\section{3 - Carótidas e Vertebrais}

A maioria dos acidentes vasculares encefálicos (AVE) é isquêmica, sendo os hemorrágicos responsáveis por apenas cerca de $20 \%$ dos casos. Entres os AVE isquêmicos, a etiologia predomi. nante é a aterosclerose carotídea, localizada, mais freqüentemente, na bifurcação. A circulação cerebral é mantida através dos sistemas carotídeo e vertebral. Denominamos troncos supra-aórticos aos grandes vasos extracerebrais responsáveis por essa circulação. Num estudo completo da circulação cerebral extracraniana, além das carótidas e artérias vertebrais, também devem ser incluídos as artérias subclávias e o tronco braquiocefálico. A tecnologia atual inclui imagem bidimensional de alta resolução, mapeamento de fluxo a cores, localizando rapidamente os distúrbios de fluxo; o power Doppler, que é uma técnica que mapeia os fluxos pela amplitude do sinal, sendo mais sensível que o color em situações de baixo fluxo, e o Doppler espectral pulsado, que fornece a medida das velocidades dos fluxos, considerada ainda o principal crité. rio para quantificação das estenoses.

\section{1 - Indicações}

\begin{tabular}{|lc|}
\hline Indicações & CLASSE \\
\hline Acidente vascular encefálico isquêmico, & \\
Isquemia cerebral transitória & $\mathrm{I}$ \\
Sopro na região carotídea & $\mathrm{I}$ \\
Amaurose fugax & $\mathrm{Ila}$ \\
Pré-operatório de cirurgia de revascularização & \\
miocárdica > 65 anos & $\mathrm{Ilb}$ \\
Pré-operatório de cirurgia de revascularização & \\
miocárdica / arterial <65 a & $\mathrm{Ilb}$ \\
Acompanhamento evolutivo de estenose carotídea & \\
(<50\%) conhecida & $\mathrm{Ilb}$ \\
Avaliação em pacientes com aterosclerose importante & $\mathrm{Ilb}$ \\
em outros territórios & $\mathrm{Ilb}$ \\
Tonteiras com fatores de risco & $\mathrm{III}$ \\
Avaliação da espessura do complexo média íntima / triagem & $\mathrm{III}$ \\
Síncope & $\mathrm{III}$ \\
Acidente vascular encefálico em jovens & \\
Tonteiras sem fatores de risco &
\end{tabular}

\section{2 - Contra-indicações / limitações}

Não existem contra-indicações para a realização do eco Doppler. As limitações que podem prejudicar a realização do exame ou a sua acurácia são as seguintes: pescoços curtos, grossos; pacientes com curativos, feridas ou cateteres na região a ser examinada; pacientes agitados, não cooperativos; pacientes com placas extensas calcificadas, que formam sombra acústica e dificultam a visualização da bifurcação.

\section{3 - Protocolo do exame}

3.3.1 - Posição do paciente - O paciente é posicionado em decúbito dorsal, com a cabeça não flexionada, levemente voltada para o lado oposto ao examinado. Em geral, retiram-se almofadas ou travesseiros. A imagem é posicionada na tela, de forma que a porção cefálica seja demonstrada à esquerda no plano longitudinal (a orientação oposta utilizada em cardiologia é aceitável). Ao plano transversal, as estruturas direitas são demonstradas à esquerda. Deve-se tomar o cuidado de não comprimir exageradamente os tecidos com o transdutor: as estruturas venosas anteriores à carótida não devem estar colabadas.
O examinador e o equipamento tanto poderão ficar à direita ou à esquerda, conforme a preferência do examinador. Alguns serviços especializados em carótidas preferem o acesso por detrás da cabeça do paciente.

3.3.2 - Equipamento - Transdutores lineares com freqüências na faixa entre 4 e $10 \mathrm{MHZ}$ (multifreqüenciais ou banda larga, dependendo do equipamento), em geral, são suficientes para a maioria dos exames. Em algumas situações, um transdutor setorial de alta freqüência, entre 4 e $7 \mathrm{MHZ}$ pode ser útil, como nas lesões proximais na base do pescoço ou lesões distais do ramo interno.

3.3.3 - Controles - Habitualmente, os equipamentos possuem aplicativo específico para exame de carótidas, tornando automática a seleção de profundidade, PRF, filtros e pacote de medidas. Cuidados especiais devem ser tomados para a utilização correta do controle de ganho, correção do ângulo e inclinação da caixa de amostragem do mapeamento de fluxo a cores.

A medida da velocidade do fluxo sanguíneo depende da correção do ângulo, que não deverá ultrapassar os 60 graus.

\section{4 - Seqüência do exame}

O exame deve ser iniciado com o corte transverso da carótida comum, a partir da fossa supraclavicular, lateral ao músculo esternocleido, fazendo uma varredura em direção ao ângulo da mandíbula. Junto à artéria carótida há a veia jugular, que não deve ser colabada. Neste corte transverso da carótida comum e ramos, serão avaliadas as placas e irregularidades destes vasos e medido também o espessamento intimal máximo da carótida comum. A carótida comum tem uma dilatação após o seu terço distal, região denominada de bulbo carotídeo, que deve ser analisada com muito cuidado, por ser o sítio mais comum de localização das placas ateroscleróticas. Após o bulbo, encontram-se os ramos interno e externo. O ramo interno costuma ser mais calibroso que o ramo externo, não emite ramos na sua porção extracraniana e tem localização mais posterior. O ramo externo emite ramos, é menos calibroso. Para sua melhor visualização, é necessário direcionar a orientação do feixe de ultra-som mais anteriormente. O primeiro ramo visualizado da carótida externa é a artéria tireóidea superior. Com a análise do corte transverso, são feitas quantificações do grau de obstrução e morfologia das placas. Neste mesmo corte, é possível verificar se a placa está localizada na parede anterior, posterior ou lateral do vaso.

A etapa seguinte consiste em avaliar a carótida comum e seus ramos em corte longitudinal, onde é obtida noção mais adequada da extensão das placas e de tortuosidades dos vasos, também chamadas de Kinking. Por último, usa-se o color Dopplere o power Doppler, que fornecem o sentido do fluxo e áreas de turbulência, dados muito importantes para utilizar, de forma adequada, o Doppler pulsado na quantificação das estenoses. O Doppler pulsado deve estar alinhado da forma mais paralela possível com o fluxo carotídeo. Caso necessário, pode-se usar o recurso de correção do ângulo para buscar esse paralelismo, desde que essa correção não seja superior a 60 graus. Com o Doppler pulsado, registram-se fluxos em carótida comum, ramos interno e externo. A carótida interna apresenta fluxo com característica de baixa resistência, com importante fluxo sistodiastólico; a carótida externa apresenta fluxo de alta resistência, com diminuição do componente 
diastólico; e a carótida comum tem padrão misto. Deve-se colocar o ponto de amostra do Doppler pulsado no local de maior turbulência, nas placas (pré, per e pós placas). O ponto de amostra não deve ultrapassar mais do que $50 \%$ da luz do vaso e não deve estar encostado nas paredes dos vasos, para evitar falsas turbulências.

Após análise da carótida comum e ramos, faz-se o estudo das artérias vertebrais, para cuja visualização podem ser utilizadas duas técnicas muito difundidas. A primeira permite visualizar a artéria subclávia na fossa supraclavicular e seguir a artéria vertebral desde sua origem, até ela mergulhar num corpo vertebral. Outra possibilidade é, a partir da visualização da carótida comum no corte longitudinal, colocar o transdutor em plano posterior para observar os processos transversos dos corpos vertebrais e fazer uma varredura deste vaso até sua origem na subclávia. Devese sempre registrar o fluxo nas artérias vertebrais bilateralmente.

\section{5 - Critérios diagnósticos}

Dois critérios diagnósticos são importantes na caracterização da gravidade de uma lesão carotídea. O mais conhecido e sempre considerado mais importante é constituído pelas velocidades de fluxos nos locais de fluxo turbulento, onde habitualmente a placa aterosclerótica produz maior redução da luz do vaso. Entretanto, hoje, considera-se a morfologia da placa tão importante quanto os distúrbios de fluxo, visto que placas chamadas de vulneráveis, tais como as placas móveis, as ulceradas, as escavadas e as com hemorragia intraplaca, embora possam não causar obstrução sig. nificativa, pelo seu potencial emboligênico, são consideradas passíveis de abordagem mais agressiva., Na elaboração do laudo, a morfologia das placas deve anteceder a descrição dos fluxos.

\section{6 - Morfologia da placa}

Algumas características das placas são importantes e devem ser lembradas na elaboração do laudo.

3.6.1 - Ecogenicidade - As placas podem ser muito ecogênicas, ditas hiperecóicas, como as placas mais calcificadas, que fazem sombra acústica, ou hipoecóicas, como as placas ditas moles. As placas isoecóicas têm ecogenicidade semelhante à do músculo esternocleido

3.6.2 - Textura - As placas podem ser homogêneas, constituídas principalmente de um material p.ex, lipídico, ou placas heterogêneas, quando na sua composição há mais de um elemento, como nas placas fibrocalcificadas.

3.6.3 - Superfície - As placas podem ter superfície regular ou irregular. Dentre as placas com superfície irregular, as mais graves são as placas ulceradas e as placas escavadas, que possuem alto poder de embolização.

3.6.4 - Formato/localização - As placas podem ter formato circular ou semicircular e podem se localizar na parede anterior, posterior, lateral ou medial do vaso. Deve ser utilizado o corte transversal para esta caracterização.

3.6.5 - Anatomia dos vasos - Deve-se relatar se os vasos são tortuosos e/ou dilatados. As tortuosidades mais acentuadas de carótidas costumam ser também chamadas de Kinking. A presença de artérias vertebrais de calibres diferentes não é rara, constituindo uma variação anatômica.

3.6.6 - Tamanho das placas - Utilizando o corte longitudinal, fornece-se a extensão da placa e se esta se prolonga em direção aos ramos.

\section{7 - Distúrbios de fluxos correlacionados ao grau de estenose do ramo interno}

Cabe ressaltar que os métodos de classificação de estenose baseados em velocidades foram feitos utilizando-se como padrão ouro a angiografia carotídea. A classificação baseada na redução da luz pela angiografia foi realizada comparando-se a redução da luz no local da placa em comparação com o leito distal do ramo interno, ou comparando-se a redução da luz no local da placa (luz residual), com o diâmetro do vaso no local da placa. Estes métodos apresentam medições diferentes.

3.7.1- Tabela de Strandness - Esta tabela é a mais conhecida e difundida entre os ecocardiografistas, mas tem como limitação um intervalo muito grande para as lesões entre $50.79 \%$. Cabe ressaltar que, em estudos que causaram impacto na indicação de endarterctomia carotídea, como o NASCET, a indicação se faz para lesões $>70 \%$, enquanto que, no estudo ACAS, a indicação se faz para lesões $>60 \%$. Após a publicação desses estudos, novas tabelas foram descritas, e o índice de Moneta logo ganhou popularidade, para estratificar lesões $>70 \%$.

3.7.2 - Índice de Moneta - Este índice ficou consagrado, devido a sua fácil execução e boa correlação para estratificar lesões acima de $70 \%$. Consiste em dividir a maior velocidade encontrada no ramo interno (numerador) pela velocidade na carótida comum (denominador). Se esta relação for igual ou maior que 4.0 , considera-se a lesão maior do que $70 \%$.

3.7.3 - Tabela da Mayo - Esta tabela vem sendo muito utilizada e permite diferenciar as lesões entre 50-70\%. Ainda existe uma limitação e falta de consenso para estabelecer lesões acima de $60 \%$.

\begin{tabular}{|lcc|}
\hline GRAU DE LESÃO & $>50 \%$ & $>70 \%$ \\
VELOCIDADE SISTÓLICA & $130-229 \mathrm{~cm} / \mathrm{s}$ & $>230 \mathrm{~cm} / \mathrm{s}$ \\
VELOCIDADE DIASTÓLICA & $>40 \mathrm{~cm} / \mathrm{s}$ & $>70 \mathrm{~cm} / \mathrm{s}$ \\
RI/CC & $1.6 \cdot 3.1$ & $>3.1$ \\
\hline
\end{tabular}

\section{8 - Limitações}

Em vasos muito tortuosos, pode ocorrer aumento de velocidade no ramo interno, simulando uma estenose grave. A utilização do color Doppler e do power Doppler permite identificar essas tortuosidades com mais facilidade.

Outra limitação pode acontecer em lesões muito graves, chamadas de subtotal, em que se podem registrar baixas velocidades, pré e pós-lesão.

Em caso de variação anatômica acentuada, como p.ex, uma carótida comum com calibre aumentado (dilatação arterial) ou um ramo interno hipoplásico, pode haver diferenças de fluxos, como se o fluxo da carótida comum fosse hiperfluxo ou houvesse uma estenose no ramo interno.

Outra limitação ocorre na presença de lesões seqüenciais, quando uma primeira lesão grave pode dificultar o diagnóstico da lesão subseqüente.

\section{9 - Estenose da artéria vertebral}

Ao contrário do ramo interno da carótida, a quantificação da estenose da artéria vertebral apresenta algumas limitações técnicas. Em primeiro lugar, aparece a dificuldade de visualizar toda a extensão da vertebral, lesões intracranianas ou em sua origem. 
Outra questão são as variações anatômicas, mais comuns na vertebral do que na carótida. Também ocorrem dificuldades de alinhar o Doppler. Alguns autores não consideram as velocidades em vertebral tão importantes para validar estenoses significativas, mas outros consideram velocidades sistólicas $>100 \mathrm{~cm} / \mathrm{s}$, compatíveis com lesão > 50\%. É bom lembrar que, mesmo em vigência de lesão vertebral importante, pode não haver correlação de sintomas, em função de circulação colateral desenvolvida pelo polígono de Willis.

\subsection{0 - Roubo de subclávia}

Esta situação ocorre na vigência de uma obstrução importante ou oclusão da artéria subclávia proximal, em que as artérias do braço serão supridas pelo fluxo reverso da vertebral do mesmo lado. Este roubo pode ser permanente ou provocado por manobras que solicitem maior aporte de fluxo nos braços, como o aperto de mão (hand grip).

\subsection{1 - Elaboração do laudo}

Deve-se estabelecer uma rotina de laudo e procurar mantê-la, evitando, desta forma, esquecer de relatar algo. Pode-se utilizar o computador para colocar um laudo pré- formatado e acrescentar somente as modificações necessárias.

3.11.1- Qualidade técnica do exame - Neste tópico, deve-se citar como exame de boa ou razoável qualidade técnica ou, então, exame limitado tecnicamente e citar a condição, p.ex; biótipo ou edema de pós operatório ou não cooperação por parte do paciente.

3.11.2 - Anatomia e morfologia dos vasos carotídeos - Neste tópico, relata-se se existe espessamento intimal (>0,9 $\mathrm{mm}$ ), se estão presentes irregularidades parietais, tortuosidades e placas. Também se descrevem detalhes morfológicos da placa, tais como localização, extensão, textura, superfície, ecogenicidade, características de vulnerabilidade e grau de obstrução baseado no exame bidimensional.

3.11.3 - Fluxos e velocidades - Caso as velocidades sejam normais, não é necessário entrar em mais detalhes no laudo. Se as velocidades estiverem elevadas, devem ser fornecidos os valores sistólicos e diastólicos dos vasos e qual critério ou tabela utilizado para caracterizar o grau de obstrução.

3.11.4 - Artérias vertebrais - Devem ser descritas características morfológicas e velocidades destas artérias e, caso não seja possível avaliar todo trajeto e origem do vaso, esta dificuldade técnica deve constar do laudo

3.11.5 - Conclusão do laudo - É o momento em que o examinador pode afirmar se os dados encontrados são sugestivos de normalidade, de doença incipiente, moderada ou grave. Deve-se ressaltar que, como todo exame complementar, necessita de correlação clínica.

\subsection{2 - Comparação com a angiografia}

O método do duplex scan vascular colorido ou Doppler colorido das carótidas e vertebrais é, hoje, um método com aceitação internacional e com vários estudos mostrando boa correlação com angiografia. Esta, atualmente, é indicada em algumas situações, tais como discrepância entre sintomas e grau de lesão, divergências com angio-ressonância, em vasos muito tortuosos ou em estudar o ramo interno. Cabe ressaltar, entretanto, que se trata de um exame invasivo e com risco de complicações. Por sua vez o duplexscan colorido é operador e aparelho dependente, demandando uma curva de aprendizado.

\section{4 - Aorta Abdominal e Artérias Renais}

\section{1 - Considerações gerais}

Para se tratar adequadamente as doenças vasculares, é fundamental fazer um diagnóstico correto e definir com precisão a localização e extensão do seu envolvimento. Diversos exames apresentam esta possibilidade.

A angiografia fornece a confirmação diagnóstica e a precisa avaliação da doença e a sua extensão; no entanto, trata-se de exame não isento de risco, não só pela técnica de realização, mas também pela utilização do contraste iodado,que pode ser nefrotóxico ou fortemente alergênico.

A ultra-sonografia abdominal tem sido de grande utilidade na avaliação das doenças da aorta abdominal e das doenças renais; porém fornece apenas informações anatômicas e estruturais (localizações, dimensões, relações).

O advento do dúplex scan permitiu a obtenção das mesmas informações do ultra-som, além da avaliação dos fluxos da aorta e das artérias renais (direção e velocidade). O constante e crescente avanço tecnológico da técnica trouxe o Doppler colorido, que fornece, rapidamente, informações a respeito da presença ou não de fluxo sanguíneo, sua direção e a avaliação grosseira da velocidade, resguardados os limites de velocidade (aliassing). O power Doppler, ainda que não permita determinar a direção ou velocidade dos fluxos, é técnica bastante sensível na detecção de baixas velocidades. Mediante esse arsenal diagnóstico, pode-se, pois, melhor entender e orientar o tratamento das doenças da aorta abdominal e das artérias renais.

Para que se obtenham elevados índices de sensibilidade, especificidade e acurácia, é imprescindível um bom equipamento, uma metodologia que forneça resultados satisfatórios para análise e um examinador experiente. Trata-se, portanto, de técnica não só de observador dependente, mas também equipamento dependente.

\section{2 - Indicações do Exame}

4.2.1 - Para aorta-abdominal -a) aneurismas (AAA): diagnóstico (classe I); acompanhamento evolutivo (classe I); pré-operatório (classe Ilb); b) acompanhamento de enxertos e endopróteses (classe Ila); c)claudicação intermitente com pulso femoral diminuído (classe I); d) dissecção da aorta (classe lla); e) arterites (classe I).

4.2.2 - Para artérias renais nativas - a) hipertensão arterial sistêmica (HAS) (classe II b); b) HAS de difícil controle clínico (classe II a); c) HAS em jovem, associada a sopro abdominal. (classe I); d) HAS de início recente ou piora acentuada de HAS pré-existente (classe lla); e) resposta exacerbada a tratamento de HAS com IECA (classe I); f) prognóstico de bom resultado para revascularização (classe lla); g) avaliação do resultado da revascularização (cirurgia ou angioplastia) (classe lla); h) envolvimento em casos de dissecção da aorta abdominal (classe lla); i) insuficiência renal + hipertensão arterial (classe I); j) assimetria renal em exame de imagem (classe Ila); k) exclusão renal em urografia excretora (classe lla). 
4.2.3 - Para transplante renal - a) seguimento pós-operatório (imediato e tardio) para identificação de complicações: vasculares (classe I); urológicas (classe llb); clínicas: rejeição (classe IIb); toxicidade por ciclosporina (classe IIb).

\section{3 - Solicitação de exames}

Os exames da aorta abdominal bem como das artérias renais devem ser sempre solicitados com Doppler colorido, pois permite a identificação de maior extensão dos vasos principais e das arté. rias do parênquima renal, mesmo nos pacientes tecnicamente difíceis, o que não é possível sem o uso do mapeamento a cores.

\section{4 - Metodologia e protocolo}

4.4.1 - Preparo do paciente - Ideal: exame pela manhã com o paciente em jejum, se possível, tendo usado 1 a 2 comprimidos de droga antiflatulenta (dimeticona $40 \mathrm{mg}$ ), na véspera à noite; opção 1: pelo menos 6 horas de jejum, tendo tomado 1 a 2 comprimidos de droga antiflatulenta, após as duas últimas refeições; opção 2: para os pacientes constipados crônicos, sugerese, além da droga antiflatulenta, a utilização de laxante na véspera do exame.

4.4.2 - Material - Preferencial: transdutor convexo de 2,5 a $3,5 \mathrm{MHz}$, aparelho que possua aplicativo para exame abdominal e Doppler colorido; opção: transdutor setorial com mesma freqüência e aparelho com ou sem Doppler colorido, porém que permita uma correção do ângulo de até $60^{\circ}$.

4.4.3 - Protocolo para aorta abdominal - Com o paciente em decúbito dorsal, obtém-se corte longitudinal da aorta, procurando visualizar o segmento proximal, ainda antes da emergência dos vasos mesentéricos. Esse segmento deverá ficar, na tela, à esquerda do examinador. Obtém-se, a esse nível, uma medida do diâmetro da aorta que deve ser confirmada no corte transverso.

Procura-se acompanhar a aorta ao longo do seu segmento proximal, identificando a emergência do tronco celíaco e da artéria mesentérica superior. Sempre utilizando cortes longitudinais e transversos, alcança-se o seu segmento distal (bifurcação das artérias ilíacas). Esse segmento poderá ser mais bem avaliado através de corte para-umbilical direito (permite avaliação da emergência das duas artérias ilíacas simultaneamente).

Deverão ser feitas medidas nos segmentos proximal $(\mathrm{N}<$ $2,0 \mathrm{~cm}$ ), médio (entre 1,5 e 2,0 cm) e distal $(\mathrm{N}<1,5 \mathrm{~cm})$, ou sempre que for evidenciada, durante o exame, qualquer variação do diâmetro do vaso. Os valores citados são para indivíduos normolíneos, podendo haver variações de acordo com a superfície corporal.

Obtêm-se fluxos com Doppler colorido e, em seguida, procurando obter o menor ângulo com o feixe de ultra-som, registram-se fluxos, cujos limites normais são extremamente variáveis de acor. do com a idade (de 0,50m/s a 1,20m/s), observando sua morfologia e medindo sua velocidade máxima.

O registro do fluxo deverá sempre ser feito com a devida correção do ângulo (no máximo $60^{\circ}$ ).

4.4.4 - Protocolo para artérias renais - Obtém-se e registrase o fluxo na aorta abdominal em corte longitudinal, 1 a $2 \mathrm{~cm}$ abaixo da emergência da artéria mesentérica superior (próximo a emergência das artérias renais), com a devida correção do ângulo. Após visualizar a emergência da artéria mesentérica superior em corte longitudinal, utilizando o corte transverso, desliza-se o trans. dutor (no sentido distal da aorta), seguindo a artéria mesentérica superior que se mantém acima da aorta na imagem; 1 a $2 \mathrm{~cm}$ abaixo evidenciam-se a veia renal esquerda, que passa entre ela e a aorta, seguindo o seu trajeto até drenar na VCI. Nessa localização, deve-se procurar, inicialmente, a artéria renal direita, que costuma emergir mais anteriormente na aorta, em posição correspondente a 10h. Havendo disponibilidade do mapeamento a cores para a realização do exame, haverá maior facilidade na localização dessa artéria que, muitas vezes, fica justaposta à veia renal esquerda. Deve-se procurar visualizar o maior segmento possível do vaso. Obtém-se fluxo na artéria renal direita com a devida correção do ângulo, registrando e medindo o pico sistólico de velocidade.

Procura-se identificar a artéria renal esquerda, que sai mais posteriormente da aorta, em posição correspondente a 4 horas, repetindo o mesmo procedimento para obtenção do fluxo.

Calcula-se a relação entre as velocidades de pico sistólico da artéria renal (AR) e da aorta (RRA) que devem apresentar valores semelhantes, ou com leve predomínio da artéria renal.

Com o paciente em decúbito lateral, utilizando cortes coronais direito e esquerdo e fazendo variar entre inspiração suave e apnéia (quando necessário), pode-se observar as artérias renais em toda a sua extensão (tarefa facilitada pelo Doppler colorido), devendose obter fluxos, medir sua velocidade sistólica nos segmentos inicial e distal ou em qualquer localização onde o mapeamento a cores mostre aumento focal da velocidade.

Em cortes longitudinais translombares, (direito e esquerdo), podem-se avaliar as artérias segmentares e interlobares, (onde deverão ser medidos o tempo e o índice de aceleração), assim como as artérias arqueadas; os índices de resistividade deverão ser determinados nas artérias interlobares ou arqueadas e em, pelo menos, quatro localizações diferentes no rim.

Nesses mesmos cortes (coronais e translombares), avalia-se a drenagem venosa renal.

Mede-se o diâmetro longitudinal do rim, observa-se sua ecogenicidade, bem como a relação corticomedular.

4.4.5 - Protocolo para rins transplantados - Os rins transplantados são de avaliação mais fácil, pois se situam mais superficialmente, na fossa ilíaca direita ou esquerda. A artéria do enxerto pode ser anastomosada de maneira término-terminal à artéria ilíaca interna ou término-lateral à artéria ilíaca externa (mais freqüente e com menor percentual de estenose da anastomose).

Dada a localização bem superficial, pode-se, muitas vezes, utilizar um transdutor de maior freqüência (5Mhz).

A metodologia do exame é bastante semelhante à da artéria renal nativa, sendo que, nesse caso, avalia-se se a artéria ilíaca à qual o enxerto está conectado não apresenta obstruções. Registra-se e mede-se o fluxo com a devida correção de ângulo, não só nessa artéria, mas também ao nível da anastomose e nos seus segmentos inicial, médio e distal da artéria renal.

As medidas em artérias segmentares, interlobares ou arqueadas também deverão ser feitas, para obtenção dos mesmos dados que para artérias renais nativas.

A seguir, deve-se avaliar a veia do enxerto e sua anastomose com a veia ilíaca.

Ao analisar o enxerto, deve-se, de igual maneira, medir e registrar o seu diâmetro longitudinal, avaliar ecogenicidade da medula, do córtex, a relação cortico-medular, bem como evidência de hidronefrose e/ ou coleções perinefréticas. 
Normatização dos Equipamentos e das Técnicas para a Realização de Exames de Ultra-Sonografia Vascular

\section{5 - Avaliação}

4.5.1 - Aorta abdominal - Diâmetros dos segmentos:

Proximal:

$2,0 \mathrm{~cm} \pm 0,3 \mathrm{~cm}$

Médio:

$1.6 \mathrm{~cm} \pm 0.4 \mathrm{~cm}$

Distal:

$1,5 \mathrm{~cm} \pm 0,5 \mathrm{~cm}$

Artéria ilíaca comum:

Definição de aneurisma: dilatação do vaso $>50 \%$ (em relação ao segmento normal imediatamente adjacente).

É importante lembrar que indivíduos normais com grandes superfícies corporais podem ter diâmetros superiores aos valores normais especificados.

Velocidade de pico sistólico (VPS)

Aorta abdominal

( $\mathrm{N} 0,70 \mathrm{~m} / \mathrm{sa} 1,40 \mathrm{~m} / \mathrm{s})$

Tronco celíaco (TC)

( $\mathrm{N} 0,86 \mathrm{~m} / \mathrm{s}$ a $1,22 \mathrm{~m} / \mathrm{s})$

Artéria mesentérica superior (AMS) (N 1,05m/s a 1,34m/s)

Artéria ilíaca comum

( $\mathrm{N} 1,00 \mathrm{~m} / \mathrm{s}$ a $1,40 \mathrm{~m} / \mathrm{s}$ )

Critérios para diagnóstico de: estenose $>70 \%$ (TC e AMS); tronco celíaco VPS $>2,00 \mathrm{~m} / \mathrm{s}$; VDF $>0,55 \mathrm{~m} / \mathrm{s}$ (N 0,32m/s a $0,35 \mathrm{~m} / \mathrm{s}$ ); mesentérica superior VPS $>2,70 \mathrm{~m} / \mathrm{s}$ VDF $>0,55 \mathrm{~m} / \mathrm{s}$ ( $\mathrm{N} 0,11 \mathrm{~m} / \mathrm{s} \mathrm{a} 0,16 \mathrm{~m} / \mathrm{s}$ )

Obstrução do segmento aorto-ilíaco $>50 \%$ : Aumento, no local da estenose, de $2 \mathrm{X}$ ou mais a velocidade obtida no segmento proximal à lesão, com perda do componente diastólico retrógrado; presença de fluxo monofásico, com velocidade diminuída e tempo de aceleração aumentado no segmento distal à lesão.

4.5.2 - Artérias renais - normal: diâmetro longitudinal do rim (N $11 \pm 1 \mathrm{~cm}$ ); velocidade pico sistólico em qualquer segmento da artéria renal principal $(100 \pm 25 \mathrm{~cm} / \mathrm{s})$; relação renal/aorta (RRA) < 3,0; tempo de aceleração hilar < 70 ms; índice de aceleração $>300 \mathrm{~cm} / \mathrm{s}$; índice de resistividade $\mathrm{N}<0,7$.

Critérios diagnósticos para : Estenose de $A R<60 \%$ :velocidade de $A R>1,80 \mathrm{~m} / \mathrm{s}$; relação renal/aorta $<3,5$; tempo de aceleração hilar< 70ms. Estenose de AR > 60\%: velocidade de AR $>1,80 \mathrm{~m} / \mathrm{s}$; relação renal/aorta $>3,5$; tempo de aceleração hilar $>100 \mathrm{~ms}$. Oclusão de $A R$ (sinais sugestivos): não detecção de fluxo na artéria renal principal; diâmetro longitudinal do rim $<9 \mathrm{~cm}$; velocidade de pico sistólico obtido em artéria intraparen. quimatosa $<10 \mathrm{~cm} / \mathrm{s}$ (ou bem menor que no rim contralateral); índice de resistividade $<0,5$. Oclusão (trombose) da veia renal: aumento dos diâmetros renais (congestão); perda da diferenciação corticomedular (congestão); veia renal dilatada, sem fluxo, com imagem sugestiva de trombo no seu interior; fluxo diastólico com direção invertida na artéria renal.

4.5.3 - Rins transplantados - velocidade na artéria ilíaca: $\mathrm{N}=0,9 \mathrm{~m} / \mathrm{s} \pm 0,2 \mathrm{~m} / \mathrm{s}$; velocidade na artéria do enxerto: $\mathrm{N}=$ 0,8 e $1,2 \mathrm{~m} / \mathrm{s}$.

Critérios diagnósticos para: Estenose de AR $>60 \%$ : VPS $>2,5 \mathrm{~m} / \mathrm{s}$ (altamente específico); relação VPS: na estenose / pré. estenose >3; relação artéria renal / artéria ilíaca > 3 .

Oclusão de AR: ausência de fluxo na artéria e veia renais. Oclusão (trombose) da veia renal: aumento dos diâmetros renais (congestão); perda da diferenciação corticomedular (congestão); veia renal dilatada, sem fluxo, com trombo no seu interior; rever-

\section{6 - Impacto diagnóstico e prognóstico}

O eco color Doppler ou dúplexscan assume grande responsabilidade não só no papel de diagnosticar as doenças da aorta abdominal e das artérias renais, como também, tendo em vista suas crescentes sensibilidade, especificidade e acurácia, como exame de grande valor preditivo e da maior importância no acompanhamento evolutivo das referidas doenças.

\section{7 - Elaboração do laudo}

4.7.1 - Aorta abdominal - a) diferenciar exame de boa qualidade técnica ou exame realizado com relativa dificuldade técnica de exame de difícil realização técnica; b) falar dos diâmetros, dos segmentos (se são normais); c) relatar se o curso for tortuoso; d) descrever as anormalidades encontradas, sempre referindo o(s) segmento(s) acometidos e a sua relação com os vasos mesentéricos ou renais; e) relatar os achados ao Doppler; f) se necessário, sugerir correlação com a clínica ou outro método diagnóstico.

4.7.2 - Artérias renais - a) referir qualidade do exame; b) referir os diâmetros somente no caso de anormalidade; c) descrever as normalidades encontradas (tortuosidades, duplicidade de artérias); d) fornecer dados com os achados do Doppler: velocidades sistólicas das AR; velocidade da aorta abdominal; relação renal/aorta; tempo de aceleração; índices de resistência; e) utilização e descrição de outros índices, como pulsatilidade, EDR, ficam a critério do examinador.

\section{5 - Artérias dos Membros Inferiores}

A avaliação das arteriopatias dos membros inferiores pelo eco Doppler tem permitido elevada acurácia em uma abordagem não invasiva de todas as doenças que acometem o sistema arterial periférico, proporcionando uma avaliação anatômica e funcional das lesões arteriais e identificando sua localização, extensão e repercussão hemodinâmica. Desta forma, representa, hoje, o método propedêutico mais versátil no estudo das doenças que acometem as artérias periféricas.

O método consiste na utilização conjunta da ultra-sonografia bidimensional de alta resolução e da avaliação com Doppler, de modo a permitir a análise simultânea da anatomia e hemodinâmica da árvore arterial periférica. A imagem bidimensional, em tempo real, possibilita a localização exata do segmento arterial, analisando seu aspecto morfológico, bem como identificação de aneurismas, trombos e caracterização de placas de ateroma (textura, calcificação e ulceração), além de permitir a exata colocação do volume de amostra do Doppler, necessária na abordagem funcional das lesões.

A análise Doppler do fluxo sangǘneo permite identificar o com. portamento hemodinâmico das lesões arteriais, através do estudo das velocidades e padrão da curva espectral nos diversos segmentos avaliados. O padrão normalmente encontrado no sistema arterial periférico é caracterizado como um sistema de alta resistência e se constitui em uma onda trifásica, que representa a interação complexa de diversos fatores relacionados com a pressão de perfusão e a resistência vascular periférica.

\section{1 - Protocolo}

Para obtenção de imagens de vasos abdominais (aorta e ilíacas), utilizam-se transdutores convexos, com freqüências que variam 
de 2,5 a 4,0 MHZ, dependendo do biótipo do paciente. Transdutores lineares são utilizados para aquisição de imagens dos mem. bros inferiores, com freqüência variando de 5 a $10 \mathrm{MHZ}$, dependendo do biótipo do paciente, vaso estudado, etc. Eventualmente, podem-se utilizar transdutores convexos para a avaliação de estruturas mais profundas, como para estudo do canal de Hunter e segmento tíbio-fibular.

Os parâmetros ultra-sonográficos são ajustados de acordo com a indicação do exame e da região anatômica a ser estudada. A imagem bidimensional é ajustada para otimizar a visualização de placas e trombos, enquanto que os parâmetros do Doppler pulsado, a cores ou power Doppler são otimizados para a correta obtenção dos fluxos normais e anormais.

O exame é iniciado em nível da porção terminal da aorta abdominal. A presença de gases intestinais pode prejudicar a adequada visualização das estruturas vasculares e, por isso, recomenda-se um jejum de $12 \mathrm{~h}$ e abstenção de alimentos que possam produzir gases. $\mathrm{O}$ uso de laxativos deve ser criterioso. Estudam-se a aorta abdominal e os vasos ilíacos com o paciente em decúbito dorsal, avaliando calibres, presença de placas de ateroma, trombos, associados ou não a estreitamento luminal. Conjuntamente, procede-se à investigação pelo Doppler (a cores ou powerDoppler), associada à obtenção das curvas espectrais pelo Doppler pulsado, analisando velocidades, curva e sinais de turbulência espectral. A introdução do mapeamento de fluxo a cores e power Doppler às técnicas Doppler permite a simultânea visualização do fluxo sangüíneo e anatomia, melhor orientação do volume amostra do Doppler, identificação rápida de pontos de turbulência (estenose) ou ausência de fluxo (oclusão), além da avaliação de colaterais e o nível de recanalização. O tempo total do exame foi reduzido em, aproximadamente, $1 / 3$ após a aquisição dessas novas moda. lidades Doppler.

O estudo dos membros inferiores é feito com o paciente em decúbito dorsal. Nele são avaliadas as artérias femorais, poplítea, tibial anterior, tibial posterior e fibular em toda sua extensão, como mencionado. Após a realização do exame, o médico deverá formular um relatório devidamente ilustrado, contendo todas as informações relevantes para a compreensão do diagnóstico do paciente.

\section{2 - Indicações}

As principais indicações deste exame são: a) avaliação diag. nóstica e acompanhamento da arteriopatia estenosante periférica; b) avaliação diagnóstica e acompanhamento de aneurismas arteriais; c) avaliação de enxertos vasculares, com acompanhamento e diagnóstico de complicações; d) avaliação diagnóstica, acompanhamento e tratamento de pseudo-aneurismas; e) avaliação diag. nóstica e acompanhamento de fístulas arteriovenosas, associadas ou não a hemangiodisplasias.

\section{3 - Obstrução arterial}

Estudam-se todos os segmentos arteriais solicitados pelo médico assistente, utilizando a imagem bidimensional (para análise morfológica do vaso e caracterização da presença de placas de ateroma ou trombose) e o Doppler (pulsado, color e/ou power Doppler) para estudo funcional da circulação. O protocolo de varredura das estruturas vasculares deve seguir o protocolo de exame.

Os estudos bidimensional e Doppler devem ser realizados de forma conjunta. Ao se identificar o vaso pelo estudo bidimensional, deve-se proceder ao estudo do fluxo sangüíneo, utilizando-se, preferencialmente, o mapeamento a cores, que possibilita a rápida identificação de distúrbios de fluxo (estenose e/ou oclusão), associada à capacidade de avaliar a presença de colaterais e/ou recanalização do vaso.

Ao se identificarem distúrbios de fluxo, deve-se utilizar o Doppler pulsado para estudo das velocidades e padrões de fluxo, a serem analisados nos seguintes pontos: a) análise da velocidade sistólica de pico (VSP) previamente à lesão obstrutiva (1 a $2 \mathrm{~cm})$; b) análise da velocidade sistólica e padrão de fluxo no ponto de menor diâmetro da lesão (orientado pelo Doppler colorido); c) análise da velocidade de pico e padrão de fluxo distalmente à lesão.

Após estudo destas variáveis, caracteriza-se o grau de obstrução (1-19\%; 20-49\%; 50-99\%; oclusão), levando em consideração a velocidade de pico, presença de sinais de turbulência espectral e perda do componente reverso. Em lesões seqüenciais, a relação VSP lesão/VSP proximal é preconizada e, quando maior do que 2, indica lesão superior a $50 \%$.

A adição do Doppler colorido e power Doppler pode auxiliar na identificação e caracterização das lesões estenóticas, podendo determinar, com exatidão, os pontos de redução intraluminal, colaterais, recanalização, bem como artérias de pequeno calibre e presença de baixo fluxo, especialmente na avaliação do leito arterial distal (run-off).

Deve-se formular um relatório devidamente ilustrado, com todas as informações obtidas durante o exame e que sejam relevantes para a compreensão do diagnóstico do paciente.

O quadro abaixo sumariza os principais achados pela análise Doppler de fluxo nas obstruções arteriais periféricas.

A sensibilidade e a especificidade do método para a identificação de lesões obstrutivas arteriais têm sido largamente avaliadas e os trabalhos já publicados confirmam que o dúplex scan colorido é o método não invasivo de escolha na avaliação de arteriopatias estenosantes periféricas. Estudos mais recentes têm demonstrado a capacidade desta técnica como método de escolha na correta avaliação pré-operatória isolada de pacientes candidatos à revascularização arterial, sendo a arteriografia utilizada apenas em casos tecnicamente inadequados.

\begin{tabular}{|lll|}
\hline Estenose & Velocidades & Curva espectral(lesão) \\
\hline Leve $(<20 \%)$ & Normais $(<120 \mathrm{~cm} / \mathrm{s})$ & Trifásica, leve turbulência espectral \\
Moderada $(20-49 \%)$ & Normais $(<120 \mathrm{~cm} / \mathrm{s})$ & Trifásica, turbulência espectral evidente \\
Severa $(50-79 \%)$ & Elevadas $(>120 \mathrm{~cm} / \mathrm{s})$ & Turbulência e alargamento espectral, perda da onda reversa \\
Crítica $(80-99 \%)$ & Elevadas $(>300 \mathrm{~cm} / \mathrm{s})$ & Turbulência e alargamento espectral, perda da onda reversa \\
Oclusão & Ausente & Ausente \\
\hline
\end{tabular}




\section{4 - Aneurismas}

Por definição, o aneurisma é uma dilatação permanente e localizada de uma artéria com diâmetro superior a 50\% do diâmetro normal esperado para aquele segmento vascular. Entretanto, como os diâmetros normais dos vasos exibem uma variação relativa. mente significativa, na dependência do sexo, idade e porte físico, bem como do método utilizado para aferi-los, ocorre dificuldade em estabelecer seus valores. Em função disto, na prática, considera-se como diâmetro "normal esperado", na presença de um aneurisma, o diâmetro imediatamente proximal à lesão.

Diante de um paciente com aneurisma arterial, os principais dados devem ser analisados ao dúplexscan colorido: a) avaliação dos diâmetros do segmento arterial acometido: longitudinal, ânteroposterior e transversal, bem como do lúmen residual, na presença de trombo; b) aferição do colo proximal e distal (dimensão transversa e longitudinal, bem como a identificação de trombos ou calcificações); c) avaliação da circulação proximal e distal ao aneurisma, bem como envolvimento de outros segmentos vasculares (ex: artérias renais e ilíacas).

O método permite a adequada visualização de aneurismas verdadeiros que acometem a aorta até o segmento tíbio-fibular. Pode ser superior à angiografia na avaliação da real dimensão de aneurismas, quando complicados por trombos intraluminais.

\section{5 - Enxertos vasculares}

O dúplex scan colorido tem sido largamente utilizado na avaliação de enxertos vasculares. Seu caráter não invasivo e de alta acurácia na avaliação dos segmentos arteriais pré e pós-enxerto, mensuração de velocidade ao nível do enxerto (importante na prevenção de trombose intraluminal), avaliação das anastomoses proximal e distal e do próprio enxerto (flaps, trombos, hiperplasia fibro intimal e/ou ateromatose), bem como a análise do leito distal possibilitam um diagnóstico precoce de falência, com correção da oclusão do enxerto. Assim, torna-se o método mais indicado na avaliação pós-operatória de implante de enxertos vasculares autólogos. Polak demonstrou sensibilidade de $95 \%$ e especificidade de $100 \%$ de detecção de estenose em próteses vasculares autó. logas. Por sua vez, Bandik mostrou que velocidades menores de $45 \mathrm{~cm} / \mathrm{s}$ ao Doppler ao nível do enxerto correlacionam-se com elevada probabilidade de trombose do mesmo. Sua detecção possibilita revisão precoce e eleva a durabilidade do enxerto. A utilização de protocolos para avaliação evolutiva pós-operatória tem diminuído, significativamente, a incidência de falência desses procedimentos. Os principais dados que devem ser demonstrados ao dúplex scan colorido podem ser assim sumariados: a) identificar inicialmente o tipo de enxerto utilizado e o procedimento realizado; b) utilizar técnica semelhante à avaliação das artérias nativas; c) realizar estudo morfofuncional inicial do enxerto, utilizando a imagem bidimensional aliada ao Doppler (colorido ou power Doppler), com varredura de todo o enxerto e atenção especial às anastomoses proximal e distal, para detecção de estreitamentos luminais, pseudo-aneurismas e fístulas; d) com base no estudo prévio, realizar avaliação com Doppler pulsado, medindo o PVS rotineiramente nos seguintes pontos: segmento arterial acima da anastomose proximal; anastomose proximal; terço médio do enxerto; anastomose distal; segmento arterial abaixo da anastomose distal. Medidas utilizadas para determinar um padrão basal impor- tante no estudo evolutivo, bem como para a identificação de lesões; e) formular um relatório devidamente ilustrado, contendo todas as informações obtidas durante o exame, relevantes para a compreensão do diagnóstico do paciente.

\section{6 - Pseudo-aneurismas}

Pseudo-aneurisma é um hematoma pulsátil, formado a partir de um pertuito em uma artéria. O seu diagnóstico é feito pela imagem bidimensional, associada ao padrão de fluxo "vai e vem" do Doppler pulsado. É registrado no canal que comunica a artéria com a cavidade, representando o fluxo de sangue em direção ao pseudo-aneurisma, durante a sístole e, em direção oposta, durante a diástole. A avaliação com dúplex scan colorido permite o diagnóstico com alto grau de acurácia, além de sua diferenciação com outras entidades, como aneurismas, fístulas arteriovenosas e massas avasculares (hematoma, abscesso, etc.). As dimensões da massa, bem como as características do lúmen (dimensões, padrão de fluxo) e do sítio de entrada e reentrada do fluxo sangüíneo, devem ser medidas, assim como deve ser avaliado se a compressão com o transdutor interrompe o fluxo no canal que o alimenta.

\section{7 - Fístulas arteriovenosas}

O dúplex scan colorido é considerado o exame não invasivo de escolha no diagnóstico de fístulas arteriovenosas congênitas e no diagnóstico de fístulas arteriovenosas adquiridas. O método permite a identificação exata do sítio de comunicação, sendo que o Doppler demonstra aspecto característico com velocidades sistodiástolicas altas, representando o gradiente elevado que existe entre a árvore arterial e venosa. A avaliação das fístulas arteriais utilizadas para hemodiálise pelo dúplex scan colorido permite identificar, com alto grau de acurácia, a presença de estenose, oclusão, trombose, aneurisma, pseudo-aneurisma e fenômeno de roubo.

\section{8 - Limitações}

O dúplex scan colorido dos membros inferiores apresenta limitações que estão relacionadas a vários fatores. Primeiramente, podem-se salientar possíveis dificuldades técnicas na obtenção de imagens em indivíduos obesos e em certas localizações, como a canal adutor, tronco tíbiofibular e bifurcação ilíaca. O dúplex scan colorido depende da utilização de aparelhagem adequada e de técnicos que estejam familiarizados com o método, bem como de profundo conhecimento da anatomia e fisiologia do sistema vascular dos periféricos e manejo das arteriopatias.

\section{6 - Trombose Venosa Profunda}

A doença vascular de mais freqüente ocorrência em pacientes hospitalizados é a trombose venosa profunda (TVP) dos membros inferiores.

Antes do desenvolvimento dos métodos de imagem, a suspeita da doença baseava-se apenas em aspectos clínicos, sendo achados mais freqüentes o edema (86,7\% dos pacientes), a dor $(86,7 \%)$, aumento da consistência muscular $(86,7)$, dor à palpação muscular $(69,7 \%)$. Entretanto, após o desenvolvimento da técnica de flebografia (Bouer-1940) ficou claramente demonstrada a baixa sensibilidade do diagnóstico clínico (em torno de 50\%). 
A flebografia, ainda considerada "padrão ouro" no diagnóstico da TVP, é um exame de difícil realização técnica, tem uma morbidade elevada (com complicações locais e sistêmicas) e sua natureza invasiva limita a sua repetição, fundamental no controle do tratamento.

Nos últimos anos, a ultra-sonografia de imagem (US) firmouse como o método de escolha para confirmação diagnóstica da TVP. Contribuiu para isto o seu caráter universal (baixo custo, presença na maioria dos hospitais, sendo os equipamentos na maior parte das vezes portáteis) e o fato de permitir um diagnós. tico não-invasivo, praticamente sem contra-indicações ou efeitos deletérios conhecidos.

O mapeamento a cores possibilita maior acurácia no diagnós. tico de TVP, principalmente nas veias da perna (infrapatelares). Baxter e cols. obtiveram sensibilidade de $95 \%$, enquanto a sensibilidade do exame, utilizando-se apenas a imagem bidimensional e o Doppler espectral para o diagnóstico de TVP nas veias infrapatelares, é inferior a $60 \%$.

\section{1 - Terminologia}

Coágulo: qualquer massa de sangue coagulado. Trombo: coágulo que se forma in situ, dentro de um vaso sanguíneo. Trombose venosa aguda: período de 2 a 3 semanas após o inicio dos sintomas, fase em que há maiores riscos de embolia pulmonar. Trombose venosa subaguda : diz respeito ao inicio de recanalização da trombose após a fase aguda. Em termos ultra-sonográficos, considera-se fase subaguda de 2 semanas a 2 meses do início dos sintomas, porém há uma grande variação de definições quanto a este período, tanto em termos clínicos, como ultra-sonográficos. A falta de definição precisa pode resultar em sérios erros de comu. nicação, devendo-se evitar o uso desta terminologia. Trombose venosa crônica : termo inadequado, que deve ser substituído por seqüela de trombose venosa. Proximal : refere-se ao envolvimento das veias do membro inferior acima do joelho (suprapatelar). Distal : refere-se ao envolvimento das veias abaixo do joelho (infrapatelar). Segmentos: cava, ilíaco, femoral, poplíteo, infrapatelar (panturriIha): inclui as veias musculares (gastrocnêmicas e soleares), as veias tibiais e peroneiras.

Para efeito prático para solicitação do exame de ultra-sonografia, deve-se separar os segmentos abdominais (cava e ilíacos) dos demais, pois, para a realização do exame no abdômen, neces. sita-se de preparo prévio para diminuição dos gases intestinais. 0 exame é realizado com transdutores convexos de menor freqüência (usualmente 3,5 MGHz), para uma maior penetração do ultrasom. Para estudo das veias femorais, poplítea e infrapatelares, entretanto, não é necessário preparo prévio, e o exame é realizado com transdutores lineares com freqüência > 5,0 MGHz. A utilização de termos, como íleo-femoral, nos pedidos de exame, causa dificuldade para autorização pelos convênios e confusão quanto ao preparo dos pacientes, devendo ser evitada. Ultra-sonografia, ecografia : refere-se somente ao exame bidimensional, não incluindo o estudo dos fluxos, sendo inadequado para o diagnóstico. Ultra-sonografia com Doppler, eco Doppler, dúplex scan : inclui o estudo bidimensional, com imagem do tecido e do fluxo sangüíneo com curvas espectrais, não incluindo o mapeamento do fluxo a cores. Embora adequado para o diagnóstico das tromboses venosas profundas proximais dos membros inferiores, tem menor sensibilidade para detecção de trombos abaixo do joelho, devendo ser evitado, principalmente nos paciente pouco sintomáticos. É inadequado também para o estudo das veias abdominais (cava e ilíacas). Ultra-sonografia com mapeamento do fluxo a cores, eco-color Doppler, dúplex scan colorido: inclui a modalidade bidimensional, o estudo dos fluxos com Doppler espectral e o mapeamento do fluxo com Doppler colorido. Adequada para o diagnóstico de trombose venosa nas veias abdominais, nas veias proximais e nas veias distais dos membros inferiores.

\section{2 - Indicações e contra-indicações}

6.2.1 - Indicações

Fatores de Risco para TVP
Idade
Trombofilias
Cirurgia
Trauma
Gravidez e puerpério
Imobilidade ou paralisia
TVP ou EP prévias
Câncer
Anticoncepcionais orais
Reposição hormonal
Insuficiência cardíaca
AVC
Tempo de cirurgia
Anestesia geral
Gravidade da doença
Quimioterapia
Obesidade
Varizes
Infarto do miocárdio

Policitemia Vera, síndrome nefrótica, doença inflamatória intestinal, vasculites.

\begin{tabular}{|lc|}
\hline Indicação & CLASSE \\
\hline Sintomas unilaterais (edema, dor, aumento da consistência & \\
muscular) em pacientes com fatores de risco. & $\mathrm{I}$ \\
Sintomas unilaterais sem fatores de risco & $\mathrm{Ila}$ \\
Sintomas bilaterais com fatores de risco & $\mathrm{Ilb}$ \\
Somente dor unilateral em pacientes com fator de risco & $\mathrm{Ila}$ \\
Edema unilateral de início recente, com fator de risco & $\mathrm{I}$ \\
Edema unilateral de início recente, sem fator de risco & $\mathrm{Ila}$ \\
Edema bilateral com fator de risco & $\mathrm{Ilb}$ \\
Edema bilateral sem fator de risco & $\mathrm{III}$ \\
Aumento do volume da panturrilha com fator de risco & $\mathrm{I}$ \\
Aumento do volume da panturrilha sem fator de risco & Ila \\
Fator ou fatores de risco sem sintomas & III \\
Pesquisa de fonte emboligênica, em paciente com & Ilb \\
embolia pulmonar & III \\
Pesquisa de trombos pós-cirurgias de risco em pacientes & \\
sem sintomas 26,43 & \\
\hline Obs: Não há na literatura consenso sobre todos os tópicos acima, deven- \\
do as indicações serem individualizadas para cada situação específica. \\
\hline
\end{tabular}

6.2.2 - Contra-indicações - Não existem contra-indicações conhecidas da utilização do Doppler colorido no diagnóstico da TVP, em nenhuma das fases evolutivas da doença. Devido ao caráter não invasivo do método, permite a realização de exames seriados 
para acompanhamento da recanalização da trombose, após o inicio da terapia e detecção precoce de complicações da TVP, como a insuficiência valvular e a obstrução por não recanalização adequada da veia.

Na fase aguda, principalmente quando se detecta a presença de trombo móvel, deve se evitar a manipulação excessiva e a realização das manobras de compressão local e distal.

\section{3 - Estratégia para o diagnóstico da TVP}

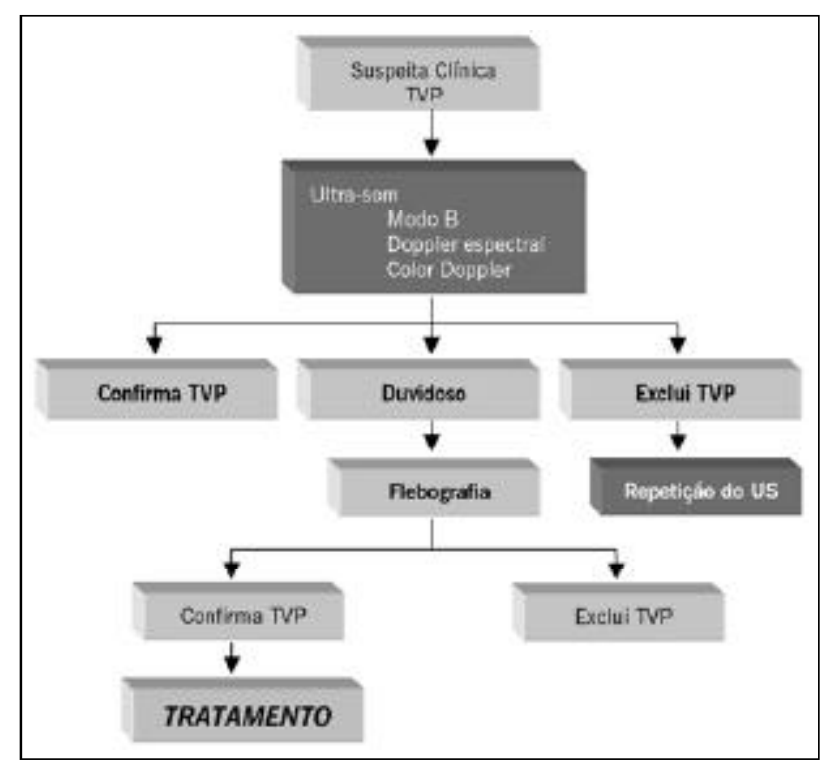

\section{4 - Técnica do exame}

6.4.1 - Posicionamento do paciente (Protocolo para pesquisa de trombose venosa) - Quando o objetivo do exame é a pesquisa de trombose venosa, o paciente deve ser posicionado em decúbito dorsal na posição de Tremdelemburg reversa, com elevação da cabeceira de 20 a 30 graus, para que haja enchimento das veias e sejam melhor visualizadas. Para o exame das veias femoral comum, femoral superficial e tibiais posteriores, o paciente deve manter a perna em rotação externa e o joelho levemente fletido. Para avaliação das tibiais anteriores, mantém-se a perna estendida com leve rotação interna. Para o exame da veia poplítea e das veias fibulares (peroneiras), o paciente pode ficar em decúbito ventral ou lateral, apoiado no membro contra-lateral e com joelho levemente fletido. $\mathrm{O}$ estudo das veias cavas e ilíacas é realizado com o paciente em decúbito dorsal, lembrando-se a necessidade de preparo prévio para diminuição dos gases intestinais.

6.4.2 - Ambiente - A sala de exame deve ser um ambiente tranqüilo e com temperatura controlada, devendo-se evitar extremos de temperatura, principalmente as muito baixas, para prevenir a vasoconstricção.

6.4.3 - Equipamento - Preferencialmente, deve-se trabalhar com equipamentos capazes de fornecer uma boa qualidade de imagem em modo B e que sejam dotados de Doppler espectral e Doppler colorido.

6.4.4 - Escolha dos transdutores - A escolha do transdutor se baseia, primordialmente, na relação freqüência do transdutor/ profundidade de localização do objeto a ser estudado. Transdutores de maior freqüência fornecem melhor qualidade de imagem, porém têm menor penetração nos tecidos. Já os transdutores de menor perda de qualidade da imagem. Habitualmente, são utilizados: transdutores convexos, com freqüência em torno de $3,5 \mathrm{MHz}$, para estudo dos vasos abdominais; transdutores lineares com freqüência entre 4 a $10 \mathrm{MHz}$, para estudo das veias profundas dos membros inferiores ou superiores; transdutores lineares com freqüência entre 7 a $13 \mathrm{MHz}$, para estudo das veias superficiais dos membros inferiores ou superiores.

6.4.5 - Otimização dos parâmetros operacionais do equipamento - A maioria dos equipamentos existente no mercado possui programas internos que otimizam automaticamente os parâmetros operacionais para tipos específicos de exames (aplicativos ou setups). Ajustes de ganho devem ser realizados para que não se perca um trombo de baixa ecogenicidade.

Controles do Doppler pulsado e Doppler colorido : ajustes devem ser feitos para detecção de fluxos de baixa velocidade (filtro baixo, PRF baixo, persistência elevada, etc.).

\section{5 - Protocolo do exame}

Segmento cava-ilíaco : com transdutor de baixa freqüência, posicionado inicialmente abaixo do apêndice xifóide, identifica-se a veia cava no eixo longitudinal. O fluxo deve ser espontâneo e fásico. Ao nível da cicatriz umbilical, inclina-se o transdutor à direita e à esquerda para se identificar as veias ilíacas comuns. Nestas veias, não é possível fazer as manobras de compressão, portanto, a avaliação das características dos fluxos torna-se fundamental. Compressão da musculatura da coxa pode aumentar o fluxo das veias ilíacas. Faz-se o mesmo procedimento em corte transverso, com o objetivo de identificar compressão da veia ilíaca comum esquerda pela artéria ilíaca comum direita (síndrome de May-Turner).

Segmento femoral : inicia-se o exame na região inguinal, obtendo-se a imagem da femoral comum e dos segmentos proximais das femorais, de forma profunda e superficial no eixo longitudinal. Posicionando-se o volume da amostra do Doppler no centro do vaso, é possível avaliar as características do fluxo, como espontaneidade e variação respiratória. Comprimindo-se a panturrilha, percebe-se o aumento do fluxo. Pede-se então, que o paciente realize a manobra de Valsalva para pesquisa de refluxo (a utilização do Doppler colorido facilita a identificação dos locais em que há refluxo, sendo a manobra de Valsalva mais apropriada para os segmentos proximais). Faz-se um leve deslocamento medial do transdutor para visualização da safena interna. Trombos podem ser vistos na imagem bidimensional, porém deve-se realizar o teste de compressibilidade dos segmentos visualizados. O transdutor é rodado em 90 graus para obtenção dos cortes transversais. Realizando manobras de compressão, move-se o transdutor distalmente até a altura do canal adutor. A utilização de corte transversal facilita a identificação de segmentos duplicados, comuns neste segmento.

Segmento poplíteo e veias musculares da panturrilha: do mesmo modo, adquirem-se imagens em modo bidimensional. Em corte longitudinal, estudam-se as características de fluxo e rodase para o corte transverso a fim de que sejam realizadas as manobras de compressão. Identificam-se os segmentos proximais e da safena externa, as veias gastrocnêmicas medial e lateral, realizandose as manobras de compressão. Com o transdutor posicionado na face medial da perna, realiza-se uma varredura em direção distal para pesquisa de veias incompressíveis ao longo dos músculos 
gastrocnêmicos e solear. Repete-se o procedimento com o transdutor posicionado na face lateral da perna. Realizando-se cortes transversos e longitudinais ao longo da panturrilha, pesquisam-se lesões de parte moles, como cisto poplíteo e hematomas musculares, que fazem parte do diagnostico diferencial da TVP e podem ser facilmente identificadas pelo US.

Segmentos infrapatelares : movendo-se o transdutor para o segmento distal da perna e posicionando-o abaixo do maléolo medial, identifica-se a artéria tibial posterior. Com manobras de compressão distal (já que, na maioria das vezes, estas veias não apresentam fluxo espontâneo), identificam-se as veias tibiais posteriores. Manobras para avaliação de refluxo são utilizadas (compressão proximal ou Valsalva associada à compressão distal). Em corte transverso, prossegue-se, cranialmente, executando-se manobras de compressão em toda extensão dos vasos. A identificação das veias peroneiras pode ser feita, colocando o transdutor posteriormente, a partir da posição inicial para estudo das tibiais posteriores

ou posicionando-o na face póstero-lateral da perna atrás da tíbia. Os mesmos procedimentos são realizados para o estudo das tibiais.

A trombose isolada das veias tibiais anteriores é rara, e essas veias não são rotineiramente investigadas, a menos que haja forte suspeita clinica de TVP e não sejam identificados trombos em outros sítios.

Troncos venosos superficiais : após o exame do SVP, retornase para região inguinal e identifica-se o local de drenagem da safena interna (SI) na veia femoral comum. Em corte transversal, examina-se toda a extensão da safena interna ao longo da coxa e perna, realizando-se manobras de compressão para pesquisa de tromboflebite superficial.

Depois do estudo da SI, com o transdutor posicionado na região da fossa poplítea, identifica-se a safena externa (SE) e, também em corte transversal, examina-se toda a extensão dessa veia.

\section{6 - Critérios diagnósticos}

\begin{tabular}{|c|c|c|c|c|}
\hline \multicolumn{3}{|c|}{ Exame Normal } & \multicolumn{2}{|c|}{ Exame Patológico } \\
\hline Características Modo B & & Fase Aguda & Fase Subaguda & Sequela de TVP \\
\hline Parede da Veia & Fina e lisa & & & Espessada e irregular \\
\hline Calibre do vaso & Normal & Aumentado & Normal ou Aumentado & Normal ou Diminuído \\
\hline Compressão das paredes & Compressível & Incompressível & Parcialmente compressível & $\begin{array}{l}\text { Compressível } \\
\text { Incompressível(Oclusão pós-trombotica) } \\
\text { ou parcialmente compressínel }\end{array}$ \\
\hline Eco intraluminal & Ausente & Pouco ecogênico & Moderadamente ecogênico & Muito ecogênico \\
\hline $\begin{array}{l}\text { Aderência do trombo } \\
\text { à parede }\end{array}$ & & $\begin{array}{l}\text { Pouco aderido } \\
\text { Pode haver áreas sem } \\
\text { adesão com Trombo Móvel }\end{array}$ & Aderido & Firmemente aderido \\
\hline \multicolumn{5}{|l|}{ DopplerEspectral } \\
\hline Fluxo & Espontâneo & Ausente & Diminuído & Espontâneo/Ausente /Diminuído \\
\hline Fasicidade & Presente & Ausente & Diminuída & Presente/Ausente/Diminuída \\
\hline Resposta à compressão distal & Aumento do Fluxo & Ausente (deve ser evitada) & Diminuída & \\
\hline Competência Valvar & Competente & Ausência de fluxo & Refluxo pode ser detectado & Refluxo freqüentemente presente \\
\hline Color Doppler & $\begin{array}{l}\text { Enche totalmente } \\
\text { a luz do vaso }\end{array}$ & Ausência de sinal & Fluxo entremeando o trombo & $\begin{array}{l}\text { Fluxo entremeando os restos } \\
\text { trombóticos/Ausente (oclusão pós-tb) }\end{array}$ \\
\hline
\end{tabular}

\section{7 - Limitações no diagnóstico de TVP}

Qualidade da imagem ruim: obesidade, volumoso edema de partes moles; dificuldade de compressão; duplicação de segmentos venosos; trombose venosa profunda recorrente; uso impróprio dos ajustes operacionais do equipamento; operador dependente.

\section{8 - Relatos da acurácia do exame}

Segmento íleo-femoral e região poplítea: especificidade e sensibilidade superior a $90 \%$ em pacientes com sintomas.

Veias da panturrilha: especificidade e sensibilidade superior a 90\% em pacientes sintomáticos.

\begin{tabular}{|lcccc|}
\hline Segmento & \multicolumn{2}{c|}{ Pacientes sintomáticos } & Pacientes assintomáticos & Referência bibliográfica \\
\hline & Sensibilidade & Especificidade & Sensibilidade & Especifidade \\
\cline { 2 - 4 } & $>90 \%$ & $>90 \%$ & & $30,31,32,33,34$ \\
Íleo-femoro poplíteo & $>90 \%$ & $>90 \%$ & $35,31,36,37$ & 38 \\
Panturrilha (quando bem visualizadas) & $60-90 \%$ & Baixa & Alta & $36,34,38$ \\
Panturrilha (quando não bem visualizadas) & & & $25 \cdot 77 \%$ & \\
Pós-Op de joelho & & & \\
\hline
\end{tabular}

\section{9 - Impacto diagnóstico}

Devido ao seu caráter não invasivo e aos altos índices de sensibilidade e especificidade (pacientes sintomáticos) e à grande especificidade em pacientes assintomáticos e os tecnicamente difíceis, o dúplex scan colorido venoso vem, progressivamente, tomando lugar de outros métodos diagnósticos. É hoje o exame de primeira escolha para o diagnóstico primário de TVP, já sendo considerado, por alguns autores, como padrão ouro para diagnós. tico da TVP.

\subsection{0 - Elaboração do laudo do exame}

No laudo, deve constar de forma clara:

Os segmentos venosos bem visualizados e os que não foram adequadamente visualizados; características das paredes das veias; compressibilidade dos vasos (caso incompressível, deve-se informar o segmento); características do fluxo venoso normal e anormal (em caso de anormalidade, deve-se especificar a manobra e o segmento); presença de trombo: ecogenicidade, aderência às paredes, presença de fluxo de recanalização. 


\section{7 - Contraste no Ultra-Som Vascular}

O primeiro relato do uso de um eco-realçador data de 1968 , quando Raymond Gramiak observou, casualmente, um aumento na intensidade do sinal de ecos provenientes das câmaras cardíacas, logo após a injeção de indocianina (44). Creditou este aumento de sinal à espuma contida na solução. Mais tarde, Carstensen e Kremkau demonstraram ser a fração gasosa, presente nesta e em outras soluções, como dextrose e solução salina agitadas, a responsável pelo aumento da intensidade dos sinal de ecos.

O contraste com microbolhas, ao contrário dos contrastes em. pregados para a ressonância nuclear magnética e para a tomografia computadorizada, que utilizam as características físico-químicas das células para o seu efeito, usa as características físicas do próprio ultra-som, ou seja, quanto maior a diferença de densidade entre os meios, maior a reflexão da energia emitida e maior a amplitude do sinal de ultra-som. Sem dúvida alguma, o meio gasoso é o que promove a maior diferença, o que, na prática, corresponde a um aumento do sinal da ordem de 30 decibéis. 0 contraste é constituído de bolhas, mais precisamente, microbolhas, com tamanho médio de 4-6 micra, enquanto que o tamanho médio de uma hemácia gira em torno de 7 micra. Outra característica interessante do contraste com microbolhas é possuir comportamento idêntico ao das hemácias no interior da circulação e microcirculação, podendo, desta forma, avaliar a integridade da microcirculação.

Atualmente, a maioria dos contrastes disponíveis comercialmente ou em fase de validação clínica, utiliza como meio gasoso os gases fluorcarbonados, que possuem um alto peso molecular, uma baixa solubilidade e uma baixa difusão, conferindo à bolha uma maior estabilidade e permitindo que ela caminhe pela corrente sanguínea, ultrapasse a barreira pulmonar sem colapsar e, com isso alcance a circulação periférica.

O emprego do ultra-som vascular está indicado nas situações onde haja diminuição do sinal de Doppler colorido ou pulsado, como em vasos de difícil acesso, em velocidades muito baixas, em que a quantidade de eco-refletores encontre-se diminuída ou exista uma dificuldade de penetração do ultra-som. Neste caso, ele é utilizado como eco-realçador, não sendo necessário o emprego de recursos, como a $2^{\mathrm{a}}$ harmônica, disponível apenas nos equipamentos mais modernos.

O desenvolvimento da $2^{\mathrm{a}}$ harmônica é ulterior ao uso do contraste como eco-realçador e veio como conseqüência da necessidade de aprimorar a técnica de perfusão miocárdica. O princípio físico da $2^{a}$ harmônica pode assim ser resumido: as bolhas, quando submetidas a um campo ultra-sônico, sofrem uma redução de seu diâmetro, por meio de uma compressão gerada por um único pulso ultra-sônico. Quando este se interrompe, elas se expandem e assumem um diâmetro maior que o original. Neste momento, elas entram em ressonância e passam a oscilar de forma não linear, emitindo freqüências harmônicas e sub-harmônicas da freqüência fundamental emitida pelo transdutor. 0 transdutor de $2^{\circ}$ harmônica capta, então, apenas a $2^{\circ}$ freqüência harmônica emitida pela microbolha, possibilitando a obtenção de um sinal mais puro e livre de artefatos e permitindo a visualização de vasos da ordem de 40 micra. Descobriu-se, contudo, que apenas um único pulso de ultra-som é capaz de destruir as bolhas, impedindo, desta forma, o preenchimento por completo da rede capilar. Um dos recursos para contornar este problema é a obtenção das imagens de forma intermitente, acopladas ao sinal do eletrocardiograma a cada um ou mais ciclos cardíacos. Perde-se, com isto, a informação do movimento, o que, para a opacificação de vísceras, como o rim, fígado e outras estruturas, passa a ter importância secundária. Mais recentemente, um novo modo de obtenção da imagem com contraste vem sendo utilizado. Este modo, com a denominação de perfusão em tempo real, permite não só a avaliação da perfusão e contração miocárdica, como também consegue, de forma mais confiável, avaliar a chegada das microbolhas na microcirculação, o que se dá graças à emissão de onda ultra-sônica com um índice mecânico (energia ultra-sônica) extremamente baixo e capaz de preservar a integridade das bolhas. Assim, após a destruição das bolhas existentes no miocárdio, através de um pulso de ultra-som de alta energia, observa-se a chegada progressiva do contraste no tecido a ser estudado. Ainda é cedo para se afirmar qual das duas técnicas é superior, necessitando-se de estudos clínicos para confirmar a eficácia de cada uma delas. Uma das grandes limitações da perfusão de órgãos e tecidos ainda é o caráter da avaliação, absolutamente qualitativo e subjetivo. Vários grupos estudam uma forma de se quantificar a diferença de vídeo-intensidade entre a imagem basal e o contraste, podendo-se, dessa forma, não somente estimar o volume sanguíneo do órgão como, também, estimar o fluxo para aquele órgão. Os softwares disponíveis comercialmente são poucos e ainda não apresentaram sua eficácia. Outros softwares desenvolvidos por algumas instituições universitárias de ponta, embora disponíveis, ainda possuem um custo proibitivo e têm, na complexidade de sua análise, o seu maior obstáculo.

\section{1 - Principais indicações para o uso de contraste no ultra-som vascular}

7.1.1 - Como eco-realçador - Dependendo do vaso a ser estudado, o grau de evidência para o uso de contraste como eco-realçador élla ou llb.

Evidência lla - Estudo das carótidas quando há suspeita de pseudo-oclusão, definição pobre da placa devido a um elevado teor de cálcio ou a placas muito extensas; estudo das artérias vertebrais em caso de visualização inadequada de seu óstio e demais segmentos e um alto grau de suspeita de insuficiência vértebro-basilar; estudo dos vasos intracranianos; estudo das artérias renais quando estas, apesar da experiência do examinador e qualidade do equipamento disponível, não podem ser visualizadas satisfatoriamente; estudo das artérias dos membros inferiores na pesquisa de perviedade, notadamente ao nível do canal dos adutores, artérias ilíacas e do segmento infrapatelar.

Evidência IIb - acompanhamento de endopróteses na pesquisa de endoleaks; pesquisa de trombose venosa em segmentos mal visualizados.

7.1.2 - Como agente de perfusão - enquanto não houver uma análise quantitativa, o grau de evidência para o seu emprego no estudo da perfusão de órgãos é llb: perfusão renal em rins nativos e enxertos renais; perfusão cerebral.

\section{2 - Estudo das carótidas}

Situações nas quais o uso do contraste pode fornecer informações adicionais ao exame basal: diferenciação entre oclusão e pseudo-oclusão carotídea; definição do lúmen residual em placas de difícil visualização, principalmente aquelas com elevado teor de cálcio, cuja sombra acústica se projeta sobre o lúmen e em placas muito extensas no ramo interno. 


\section{3 - Doppler transcraniano}

Devido ao alto índice de absorção da energia ultra-sônica por parte da calota craniana, o percentual de exames onde não se obtém um sinal adequado pode chegar a $20 \%$. Com o uso de contraste não somente se melhora a intensidade do sinal, como também, consegue-se abordar vasos mais profundos, como a artéria basilar distal e menores, como os ramos cerebelares. Outro benefício do uso do contraste é a obtenção do ângulo de abordagem do vaso que na técnica convencional freqüentemente é realizada de forma cega e com contraste, através da melhor visualização do vaso com Doppler colorido, consegue-se obter a melhor angulação possível e, desta forma, velocidades mais fiéis. Por fim, o contras. te permite aumentar a frequiência de repetição de pulso do Doppler colorido, indicando, a direção do fluxo nos vasos intracranianos, dado este importante na avaliação do padrão de circulação colateral em vigência de doença carotídea oclusiva.

\section{4 - Estudo das artérias renais}

Um dúplex scan colorido conclusivo das artérias renais requer sua visualização ao longo de todo o trajeto. O índice percentual de artérias não visualizadas ou parcialmente visualizadas é bastante variável na literatura e depende, basicamente, da experiência do examinador, da população estudada e do equipamento disponível. Observa-se, nos estudos publicados, que o uso de contraste melhora, sobremaneira, o índice de visualização das artérias renais, aumentando a acurácia, sensibilidade e especificidade do método e, também, diminuindo, significativamente, o tempo de exame.

Nos quadros clínicos em que a suspeita de estenose de artéria renal é elevada e a qualidade das imagens obtidas no exame basal não é ideal, pode-se optar pelo uso de contraste. Com isso, melhorando, assim, a visualização de todo o trajeto das artérias renais, tornando possível posicionar o ponto de amostragem ao longo da mesma, registrando-se a velocidade sistólica máxima nos diversos pontos.

\section{5 - Estudo das artérias dos membros inferiores}

A maioria dos casos pode prescindir do uso de eco-realçador, mas, em situações nas quais há muitos artefatos na região pélvica ou um fluxo muito lento nas artérias infrapatelares, o uso de contraste poderá ajudar a definir melhor a anatomia vascular.

Ocasionalmente, pode não se obter o efeito eco-realçador desejado, que pode ocorrer em alguns casos em que existe oclusão proximal e a concentração de contraste é baixa. Com o aumento da velocidade de infusão ou da concentração do contraste, quando em bolus, consegue-se melhorar o efeito pretendido.

\section{6 - Perfusão de vísceras}

A perspectiva do contraste na perfusão de vísceras é muito grande, mas, como a análise quantitativa ainda está restrita aos grandes centros universitários, o seu uso ainda depende da análise qualitativa, que, por ter um caráter subjetivo e sujeito a diferentes variáveis, pode ser falha. Atualmente, já se obtêm belas imagens de rins nativos e enxertos renais perfundidos com contraste. O potencial da técnica para demonstrar estados de hipoperfusão e/ou aumento do tempo de chegada do contraste irá permitir não somente avaliar funcionalmente a estenose renal e o estado de perfusão do rim envolvido, como também ajudará a fornecer informações prognósticas em candidatos à angioplastia. O padrão de perfusão, juntamente com outras variáveis, poderá auxiliar a identificar aqueles enxertos renais em risco de rejeição ou com outras afecções.
A perfusão cerebral já é possível, podendo se avaliar em tempo real a chegada e o grau de perfusão dos diversos territórios cerebrais. Futuramente, poder-se-á avaliar, à beira do leito, a evolução de afecções que, de alguma forma ou outra, afetam a perfusão cerebral, sua microcirculação e fluxo cerebral.

\section{7 - Material e métodos}

7.7.1 - Equipamento - Para o estudo dos vasos utilizando-se o contraste como eco-realçador, a aparelhagem de ultra-som necessária é idêntica àquela já empregada para o estudo basal, com transdutores adequados para cada região específica.

No caso de se estudar a perfusão de alguma víscera, como rim, fígado ou cérebro, será necessário o emprego de máquinas dotadas de $2^{\text {a }}$ harmônica com softwares dedicados para perfusão. O modo de perfusão, se intermitente ou em tempo real, dependerá da escolha do médico realizador e da máquina utilizada.

Em caso de opção por infusão contínua do contraste, este deverá ser infundido através de uma bomba de infusão para um melhor controle da velocidade ou, em último caso, através de um equipo de microgotas.

7.7.2 - Metodologia - Todo o exame vascular com contraste deve ser precedido de um estudo basal do vaso a ser estudado. É necessário lembrar que o operador deve não somente ter a habilidade de estudar o vaso em questão, como também ter um mínimo de conhecimentos acerca da técnica do contraste, no que diz respeito à calibragem do equipamento de ultra-som e aos princípios físicos que atuam sobre o contraste com microbolhas.

Após o estudo basal, define-se o segmento de maior interesse a ser estudado com contraste. Punciona-se veia calibrosa, a fim de diminuir o efeito irritativo que o contraste hiperosmolar pode provocar sobre a parede do vaso. A punção deve ser, preferencialmente, com um jelco, conectando-se a ele um triway. A forma de infusão, se um bolus ou infusão contínua, dependerá do contraste utilizado. Em caso de infusão em bolus, o tempo médio de efeito do contraste será em torno de 7 a 10min. Sendo assim, deve se começar o estudo pelos segmentos vasculares onde se encontra a maior dúvida. A injeção em bolus é feita lenta e continuamente e, em aproximadamente 15s, o contraste já será visualizado na circulação periférica. Neste momento, os controles de ganho do Doppler colorido, freqüência de repetição de pulso e compressão devem ser ajustados para evitar uma imagem excessivamente borrada do Doppler colorido pelo contraste. Um dos recursos possíveis é trabalhar com o modo power Doppler,que, por detectar amplitude de sinal, pode ser mais facilmente ajustado. Os controles de ganho do Doppler espectral também devem ser ajustados de acordo com a intensidade do sinal obtido.

Deve-se lembrar que o uso do eco-realçador pode gerar um aumento verdadeiro nas velocidades de fluxo. Isto se deve tanto a detecção e posicionamento do ponto de amostragem no local de maior estenose, como ao fato de o contraste realçar os componentes de maior velocidade na coluna de sangue que, de outra forma, passariam desapercebidos. Alguns contrastes podem ser infundidos de forma contínua, o que permite um tempo de exame bem mais prolongado. Nesses casos, mistura-se o contraste em uma bolsa de 100ml de soro fisiológico e infunde-se essa solução através de bomba de infusão.

A concentração do contraste e a velocidade de infusão variam de acordo com o tipo de contraste, o peso do paciente, o vaso a ser estudado, o efeito eco-realçador obtido em cada paciente e o objetivo do exame, seja o de realçar o sinal do Doppler ou perfundir 
alguma víscera. Neste último caso, será necessária uma maior velocidade de infusão. Devido à diferença de osmolaridade entre o contraste e a solução carreadora, a mistura tende a separar-se em duas fases. Uma forma de se evitar este problema é movimentar, freqüentemente, a bolsa de infusão e o equipo.

Não há relatos na literatura de efeitos colaterais graves secundários ao uso dos contrastes que já se encontram em uso comer. cial. As reações mais comuns, embora esporádicas, resumem-se a uma dor suportável na veia infundida, o que pode ser minimizado pela punção de veias maiores. Outros efeitos, como sensação de formigamento nos lábios e gosto estranho, são bem menos freqüentes. Em geral, o exame costuma ser muito bem tolerado, não havendo contra-indicações formais para o seu emprego. Deve-se, contudo, evitar o seu uso em pacientes com insuficiência cardíaca refratária, devido a uma possível sobrecarga osmolar. As demais contra-indicações devem ser individualizadas para cada tipo de contraste. Em crianças, devem ser ajustadas a concentração e a dose, de acordo com orientação do fabricante.

\section{Referências consultadas}

George A. Beller, President's page: what about the "vascular" in cardiovascular? JACC 15 November 2000, Volume 36, Issue 6 Pages 2009-10.

AbuRahmaAF, Thiele SP, Wulu JT Jr. Prospective controlled study of the natural history os asymptomatic $60 \%$ to $69 \%$ carotid stenosis according to ultrasonic plaque morphology. JVasc Surg 2002; 36: 437-42.

Ali F. AbuRahma \& John J. Bergman - Non Invasive Vascular Diagnosis, London. Springer-Verlag 2000.

Moneta GL, Edwards JM, Chitwood RW, Taylor LM, Cummings CA et al. Correlation of NorthAmerican Symptomatic Carotid Endarterectomy Trial (NASCET)angiographic definition of $70 \%$ to $99 \%$ internal carotid artery stenosis with dúplex scanning. J Vasc Surg 1993; 17: 152-7, discussion 157.9.

Huston J 3rd, James EM, Brown RD Jr, Lefsrud RD, Ilstrup DM, Robertson EF et al. Redefined dúplex ultrasonographic criteria for diagnosis of carotid artery stenosis. Mayo Clin Proc 2000; 75: 1133-40.

Polack JF. Carotid ultrasound. Radiol Clin North Am 2001; 39: 569-80.

Michael Hennerici \& Doris Neuerburg.Heusler. Vascular diagnosis with ultrasound. Thieme 1998

Rothwell PM, Eliasziw M, Gutnikov SA, FoxAJ, Taylor DW, Mayberg MR et al. Analysis of pooled data from the randomised controlled trials of endarterectomy for symptomatic carotid stenosis. Lancet 2003; 361: 107.16.

Sacco RL. Clinical practice. Extracranial carotid stenosis. N Engl J Med 2001; 345: 1113.8.

Bernstein EF. Vascular Diagnosis. $4^{\mathrm{a}}$ edição, 1993, seção III.

Zwiebel WJ, Introduction to Vascular Ultrasonography, $4^{\text {a }}$ edição. Philadelphia. WB Saunders, 2000.

Nectoux Fo JL, Cunha SS, Pagholi SA, Souza GG, PereiraAH. Ultra-Sonografia Vascular, Revinter, 2000.

Bonamigo TP, Von Ristow A. Aneurismas, RJ, AGE, 1999

Safian RD, TextorSC. Renal Artery Stenosis. NewEng J Med, Feb 8/2001, V344,(431-42)

Ricci MA. Renal Artery Duplex University of Vermont, Department of Surgery, Division of Vascular and TransplantSurgery. September 29, 1997. (internet: www.vtmed.org/ vascular/rad.htm)

Radermacher J et al. Detection of significant renal artery stenosis with color Doppler sonography: combining extrarenal and Intrarenal approaches to minimize technical failure. Clinical Nephrology. N-5; V53; 2000 (333-43).

Reynolds T et al. The Evaluation of the Abdominal Aorta: A "How-to" for Cardiac Sonographers. J Am Echo N4; V3; 1999 (336-46).

RumackCM, Wilson SR, Charboneau JW. Tratado de Ultra-sonografia Diagnóstica. $2^{\text {a }}$ edição, RJ Guanabara Koogan, 1999.

Brito CJ. Cirurgia Vascular. RJ Revinter, 2002, 2 vols. 2002, 1512p.

Elsman BH, Legemate DA, van der Heidjen. Impact of ultrasonography dúplex scanning on therapeutic decision making in lower-limb arterial disease Br J Surg 1995; 82 630.3.

Ligush J, Reavis SW, Preisser JS. Duplexultrasound scanning defines operative strategies for patients with limb-threatening ischemia. JVasc Surg 1998; 28: 482-91.

Walsh DB, Lombard E. Lower extremity bypass using only dúplexultrasonography: the time now? Semin Vasc Surg 1999; 12:247-51.

Zierler RE. Vascular Surgery without arteriography: use of Dúplexultrasound. Cardiovasc Surg 1999; 7: 74.82.

Bernstein, EF. Vascular Diagnosis - 4 ed. - Mosby-1993, 1058p.

Strandness, DE. Dúplex Scanning in Vascular Disorders - 2 ed. - Raven Press - 1993. 329p.

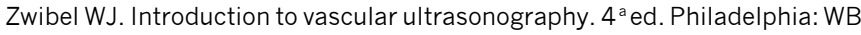
Saunders, 2000.

Mafei, Francisco H. Doença Vascular periférica-3a ed. RJ: MEDSI, 2002.

Thomaz, João Batista. Síndromes Venosas: Diagnostico e tratamento · $1^{\text {a ed. RJ: }}$ Revinter, 2001.

Hach/Hach. Wunderle, Phebographie der Bien und Beckenvenes (Phlebogra and sonography of the veins) Merlin: Verlag, 1997.
Sullivan ED, Peters BS, Cranley JJ. Real Time B-mode venous ultrasound. J Vasc Surg 1984; 1: 465471.

Vogel P, Laing FRC, Jeffrey RB et al. Deep venous trombosis of the lower extremity: US evaluation. Radiology 1987; 163: 747

Appelman PT, De Jong TE, Lampmann LE. Deep venous trombosis of the leg: US findings. Radiology 1987; 163: 743-6.

O'Leary DO, Kane R, Pinel D et al. A prospective study of the efficacy of B-scan sonography in daetection DVT in lower extremity. Presented at the American Institute of Ultrasound in Medicine Annual Convention, Las Vegas, NV, 1986.

Comeroto AJ, Katzs ML, Hashein MA. Venous Dúplex imaging for diagnoses of acute deep venous thrombosis. Hemostasis 23 (supp 1): 1993;61-71.

Oliver MA. Duplex scanning in venous disease. Bruit IX: 206-209,1985. In: ZwiebelWJ, Introduction to vascular ultrasonography. $4^{\circ} \mathrm{ed}$. Philadelphia: WB Saunders, 2000.p. 321

Polak JF, Culter SS, O'Lary DH. Deep vein of the calf: Assessment with color flow Doppler imaging. Radiology 1989; 171:481-5.

Semrow CM, Friedell ML, Buchbinder D etal. The efficacy of ultrasonic venography in detection of calf vein thrombosis. Presented at the Tenth Annual Meeting of the Society of Non-invasive Vascular Technology, Toronto, Canada, 1987.

Duzat MM, Laroche JP, Charras C et al. Real-time B-mode ultrasonography for better specificity in the non invasive diagnosis of deep venous trombosis. JUltrasound Med 1986; 5: 625-31.

Bouer G. Venographic study of thrombo-embolic problems. Acta Chir Supp 1940; 61:1.75.

Wheeler HB, Anderson FA. Diagnostic methods for deep veis thombosis. Haemostasis 1995; 25: 6.26.

Mattos MA, Londrey GL, Leutz DW et al. Color flow duplex scanning for surveillance and diagnosis of acute deep venous thrombosis. J Vasc Surg 1992; 15: 366-76.

Baxter GM, Duffy P, Patridg E. Colour flow imaging of calf vein thrombosis. Clinical Radiology. 1992; 46: 198-201.

Rose SC, Zwibel WJ, Miller FJ. Acuracy of color flow duplex sonography for diagnosis of lower extremity deep venous thrombosis. Presented at 17 scientific assembly of radiological society of North America, Chicago, 1999.

GramiakR, Shah PM. Echocardiography of the aortic root. Invest Radiol 1968; 356-66.

Nanda NC, SchliefR, Goldberg. Advances in Echo Imaging using ContrastEnhancement Kluwer Academic Publishers-2ed.

Droste DW, Jurgens R, Nabavi DG, Schuierer G, WeberS, Ringelstein EB. Echocontrastenhanced ultrasound of extracranial internal carotid artery high-grade stenosis and occlusion. Stroke 1999; 30: 2302-6.

Ferrer JM, Samso JJ, Serrando JR, Valenzuela VF, Montoya SB, Docampo MM. Use of ultrasound contrast in the diagnosis of carotid artery occlusion. JVasc Surg 2000; 31:736-41.

Baumgartner RW, Arnold M, Gonner Fetal. Contrast-enhanced transcranial color-coded dúplex sonography in ischemic cerebrovascular disease. Stroke 1997: 28: 2473-8.

Droste DW, Jurgens R, Weber S, Tietje R, Ringelstein EB. Benefit of echocontrastenhanced transcranial color-coded dúplexultrasound in the assessment of intra. cranial collateral pathways. Stroke 2000; 31:920-3.

Iglseder B, Huemer M, Staffen W, Ladurner G. Imaging the basilar artery by contrast. enhanced color-coded ultrasound. J Neuroimaging 2000; 10: 195-9.

Claudon M, Plouin PF, Baxter GM, Rohban T, Devos DM. Renal arteries in patients at risk of renal arterial stenosis: multicenter evaluation of the echo-enhancer SH U 508A at color and spectral Doppler US. Levovist Renal Artery Stenosis Study Group. Radiology 2000; 214: 739-46.

Ubbink DT, Legemate DA, Llull JB. Color-flow dúplex scanning of the leg arteries by use of a new echo-enhancing agent. J Vasc Surg 2002; 35: 392-6.

Wei K, Le E, Bin JP, Coggins M, Thorpe J, Kaul S. Quantification of renal blood flow with contrast-enhanced ultrasound. J Am Coll Cardiol 2001; 1537: 1135-40.

Rim SJ, Leong.Poi H, Lindner JR et al. Quantification of cerebral perfusion with "RealTime" contrast-enhanced ultrasound. Circulation 2001;20; 104: 2582-7. 